\title{
Mixing Fillers-The Reversal Problem
}

\author{
James Webster ${ }^{1 *}$ and Alice Cameron ${ }^{2}$ \\ ${ }^{1}$ Dental Core Trainee in Oral \& Maxillofacial Surgery, Department of Orthodontics \& Maxillofacial \\ Surgery Royal United Hospital, NHS Foundation Trust, Combe Down, BA1 3NG, England, UK \\ ${ }^{2}$ Specialty Dentist in Oral \& Maxillofacial Surgery, Department of Orthodontics \& Maxillofacial Surgery \\ Royal United Hospital, NHS Foundation Trust, Combe Down, BA1 3NG, England, UK
}

Check for updates

Received: 23 January, 2020

Accepted: 26 February, 2020

Published: 27 February, 2020

*Corresponding author: James Webster, Dental Core Trainee in Oral \& Maxillofacial Surgery, Department of Orthodontics \& Maxillofacial Surgery Royal United Hospital, NHS Foundation Trust, Combe Down, BA1 3NG, England, UK, E-mail: james.webster@nhs.net

https://www. peertechz.com

\section{Abstract}

Background: Injection of dermal fillers has become one of the most frequent cosmetic procedures. Serious complications as a result are rare but can result in devastating results for both patient and clinician. Skin necrosis is one of the most severe complications and considering this, there is only very minimal incidence of such events reported in the literature along with diagnosing and treating this adverse event. Reversal agents can often resolve such complications; however, this article looks at the challenges when such agents are unavailable.

Methods: We present a case of a 32-year-old gentleman who suffered from skin necrosis as a consequence of a mixed hyaluronic acid and calcium hydroxyapatite cosmetic injectable filler and discuss the diagnosis and possible treatment plan accompanied by avoidance of such adverse side effects.

Conclusion: Skin necrosis associated with dermal fillers is a rare event but is an important risk factor to discuss when consenting individuals for the procedure. The increasing use of Calcium Hydroxyapatite as an additive to hyaluronic acid means that fillers cannot be reversed as straight forwardly leading to a higher risk of irreversible or partially reversible facial skin necrosis.

\section{Introduction}

Facial fillers have become increasingly popular for masking true age by hiding facial lines, creases and wrinkles but can also be used in none cosmetic procedures for correcting disabling volumetric soft tissue loss in HIV associated facial lipoatrophy, Romberg disease and post-surgical and traumatic facial disfiguration $[1,2]$. When dermal fillers are performed by experienced, well-trained practitioners, adverse events occur in less than $1 \%$ of patients and most of these are transient [3].

There are a number of studies discussing the ideal characteristics of soft-tissue filling material and the consensus on this is that the filler must have an acceptable longevity, biocompatibility, non-migratory, low adverse event profile, and a reasonable cost-benefit ratio.

Fillers can be classified chemically as being biological or synthetic. Biological include bovine collagen, animal hyaluronic acid, and autologous fat. Synthetic fillers include non-animal hyaluronic acid, Polymethyl Methacrylate (PMMA) microspheres, and hydroxyapatite micro-particles.
As well as classing these materials chemically they are also classed in terms of their longevity, short acting, long lasting or permanent [4].

In order to get both the ideal filler compatibility fillers are being increasingly used in combination to achieve the ideal outcomes as in the following case where hyaluronic acid was used with calcium hydroxyapatite. Hyaluronic Acid (HA) has become one of the most popular facial aesthetic augmentation filler agents [5]. HA is a long unbranched polysaccharide found naturally in all tissues and body fluids of vertebrates, HA has features that make it an attractive substance for dermal filler use, such as its ability to bind to large amounts of water, its natural presence in the skin, and its low potential for adverse reactions. There are many different types of HA based on its crosslinked capabilities which can change its longevity, firmness and biocompatibility [6]. Calcium Hydoxyapatite (CaHA) received food and drug administration approval for aesthetic use in 2006 for the correction of moderate to severe facial wrinkles and folds. It provides immediate correction with a 1:1 ratio of CaHA to tissue volume [7], and since its approval it has received a good safety record [8]. However, with ever 
increasing demand for facial aesthetic treatments there is higher incidence of adverse events.

\section{Case report}

A 32-year-old male presented to the A and E department in Bath, England, complaining of worsening facial swelling to his left cheek following non-surgical injection of facial fillers to augment his cheek profile. Upon discussion, this was the $8^{\text {th }}$ time he had received this treatment and explained it was carried out every 9-12months. Since treatment 2days ago he suffered from pain and a throbbing sensation to the area plus changes in the color of his skin. He described the area as feeling different and hard and painful to touch.

Medically the patient was fit and well with no known allergies. He had no underlying medical conditions or comorbidities and took no prescribed medication. He was a none smoker and rarely consumed alcohol.

On examination the patient had a firm inflamed mass in the left infraorbital region with erythema spreading laterally in a livedo pattern to a distinct margin of hyperemia surrounded a zone of dusky darkened skin. A full cranial nerve examination was carried out which was unremarkable with the exception of altered sensory sensation to the left zygomatic region $\left(\mathrm{CNV}_{2}\right)$. The patient was responsive and alert with a GCS of 15 and a temperature of $37.3^{\circ} \mathrm{C}$. A systemic examination was completed ruling out any further signs and excluding any further dermatological lesions.

The affected area had a 6second capillary refill upon palpation and was deemed to be necrotic.

The patient had been treated with hyaluronic acid and calcium hydroxyapatite in the ratio of 50:50 with $1.25 \mathrm{ml}$ of filler split evenly on the right and left side. Figure 1 is a clinical photograph taken upon completion of this examination.

\section{Differential Diagnosis}

1. Skin necrosis due to vascular complication;

a. Intra-arterial injection.

b. Extra vascular compression.

2. Hypersensitivity and inflammatory reaction. Usually caused by contamination of byproducts with bacterial fermentation [9].

\section{Necrotizing fasciitis.}

Given the clinical findings a diagnosis of skin necrosis was confirmed due to the occlusion of an arterial vessel. Treatment plan devised from The Aesthetical Complications Expert (ACE) Guidelines;

1. Hyaluronidase reversal agent (200-400 IU/ 1-2ml) + massage.

2. Topical GTN patch to encourage vasodilation.
3. Warm pack to left zygomatic region to encourage vasodilation

4. 6.6mg Dexamethasone IV Stat.

5. Outline periphery of lesion with skin marker to assess for improvement or deterioration.

Following 24 hours of inpatient hospital care the patient was discharged following marked reduction in symptoms and reduced swelling, erythema and reduction in the dusky appearance noted upon presentation (Figure 2). The patient was subsequently followed up at 3day intervals for 2 weeks to ensure full resolution.

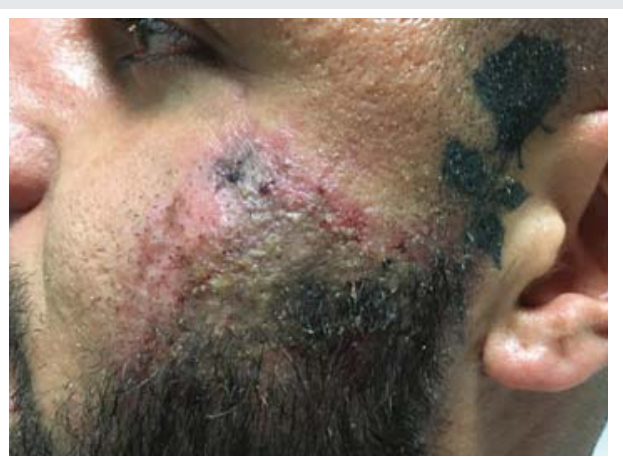

Figure 1: Clinical photograph taken upon completion of this examination.

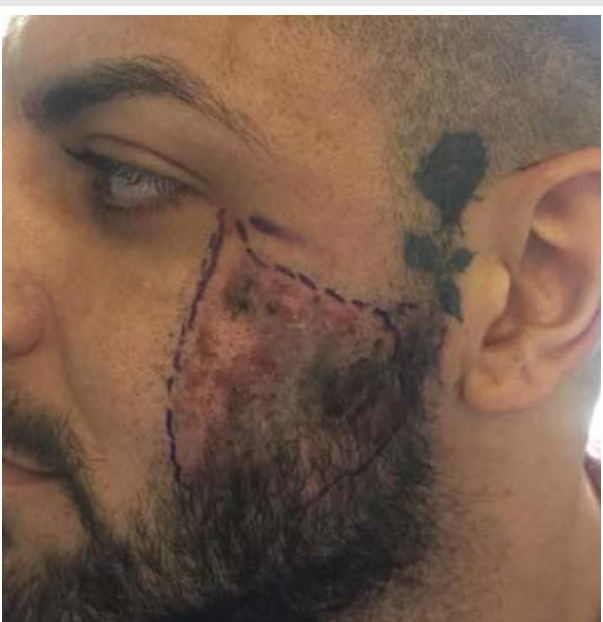

Figure 2: Following 24 hours of inpatient hospital care the patient was discharged following marked reduction in symptoms and reduced swelling, erythema and reduction in the dusky appearance noted upon presentation.

\section{Discussion}

Every aesthetic procedure has its potential risks, and each individual case is uniquely different. Specific regions of the face are at a higher risk for complications due to critical structures and the vascular system that supplies each area, the glabella and nasolabial fold being higher risk sites [10]. It's important that clinicians have an understanding of potential structures that could cause complications prior to surgery, knowing the specific techniques to administer each dermal filler and volume enhancer, knowing which specific high-risk areas to avoid, and 
knowing what to do if complications occur form the basis to ensure safe and optimal clinical outcomes with augmentation procedure. There is an argument to include this as standard in the undergraduate dental program to standardize training, improve patient protection and to regulate the industry [11].

The recommendation that fillers should be distributed via small boluses of $0.1 \mathrm{~mL}$ or less should be balanced by the risk of injecting a larger number of sites, along with the difficulty of getting reliable flashback into the syringe through fine needles filled with thick gels [12]. Deep tissue scars may stabilize and fix arteries in place, making them easier to penetrate with small sharp needles as in the above case, previous injections to the same site is likely to increase the risk of intra-arterial injection.

Although injecting high volumes into an individual site may cause external vascular compression, attempting to recreate this mechanism has failed [13]. The more likely mechanism of skin necrosis following fillers is intra-arterial injection. The human face has a rich vascular network, and given the numerous collaterals and anastomoses present between vascular areas, it presents a target-rich situation. However, the presence of collateral pathways is also protective obstruction of any particular pathway often opens alternatives to provide satisfactory blood supply [13].

The clinician treating the above patient had combined filling materials using both HA and Calcium Hydroxyapatite meaning that only the HA aspect could be reversed using the hyaluronidase reversal agent [14]. Although evidence is emerging of possible CaHA reversal agents in the form of sodium thiosulfate, not enough in vivo testing has been carried out to make this at present a viable solution. Therefore, there is a higher risk that the blood supply to this tissue will be occluded for a greater amount of time, increasing complication risks following inter-arterial injection.

\section{Conclusion}

The use of dermal fillers for facial aesthetics is increasing rapidly, due in large part to enhanced public interest in these products, and a larger range of effective options available for a number of cosmetic enhancements. A thorough understanding of facial anatomy is required by the clinician including a consideration into product selection and placement. Should early side effects be noted such as blanching of the skin, these should be treated early to avoid more serious complications as in this case. Although serious complications are rare, clinicians require suitable training in order to manage them early and correctly. More research is required into reversal agents for
CaHA and this should be considered by clinicians when deciding whether it should be used in conjunction with hyaluronic acid.

\section{Consent}

Full written consent was achieved from the patient to publish the case findings.

\section{References}

1. Becker M, Balagué N, Montet X, Calmy A, Salomon D, et al. (2015) Hyaluronic acid filler in HIV-associated facial lipoatrophy: Evaluation of tissue distribution and morphology with MRI. Dermatology 230: 367-374. Link: http://bit.ly/2T3pHSZ

2. Onesti MG, Troccola A, Scuderi N (2009) Volumetric correction using poly-Ilactic acid in facial asymmetry: Parry romberg syndrome and scleroderma. Dermatologic Surg 35: 1368-1375. Link: http://bit.ly/2HYbHDZ

3. Alam M, Kakar R, Nodzenski M, Ibrahim O, Disphanurat W, et al. (2015) Multicenter Prospective Cohort Study of the Incidence of Adverse Events Associated With Cosmetic Dermatologic Procedures. JAMA Dermatology 151: 271. Link: http://bit.ly/3cgo0cK

4. Jacoveila PF (2008) Use of calcium hydroxylapatite (Radiesse®) for facial augmentation. Clinical Interventions in Aging 3: 161-174. Link: http://bit.ly/2TOUiAO

5. Rzany B, De Maio M (2006) Injectable fillers in aesthetic medicine. Link: http://bit.ly/2Ps1NP2

6. Tezel A, Fredrickson GH (2008) The science of hyaluronic acid dermal fillers. Journal of Cosmetic and Laser Therapy 10: 35-42. Link: http://bit.ly/3chLm1F

7. Robinson DM (2018) In Vitro Analysis of the Degradation of Calcium Hydroxylapatite Dermal Filler: A Proof-of-Concept Study. Dermatol. Surg 44: S5-S9. Link: http://bit.ly/2lbZI5T

8. Kadouch JA (2017) Calcium hydroxylapatite: A review on safety and complications. J Cosmet Dermatol 16: 152-161. Link: http://bit.ly/32x1Xdd

9. Van Dyke S, Hays GP, Caglia AE, Caglia M (2010) Severe acute local reactions to a hyaluronic acid-derived dermal filler. J Clin Aesthet Dermatol 3: 32-35. Link: http://bit.ly/397phk4

10. Brennan C (2015) Avoiding the 'danger Zones' when injecting dermal fillers and volume enhancers. Plast Surg Nurs 34: 108-111. Link: http://bit.ly/37Y06gJ

11. Walker TWM, Gately F, Stagnell S, Kerai A, Mills C, et al. (2017) Can UK undergraduate dental programmes provide training in non-surgical facial aesthetics? Br Dent J 222: 949-953. Link: https://go.nature.com/2PuMAfZ

12. Delorenzi C (2014) Complications of injectable fillers, Part 2: Vascula complications. Aesthetic Surg J 34: 584-600. Link: http://bit.ly/3c8tKVT

13. Camacho D, Machan S, Pilesanski U, Revelles JM, Martín L, et al. (2012) Generalized livedo reticularis induced by silicone implants for soft tissue augmentation. Am J Dermatopathol 34: 203-207. Link: http://bit.ly/3821lxn

14. Rao V, Chi S, Woodward J (2014) Reversing facial fillers: interactions between hyaluronidase and commercially available hyaluronic-acid based fillers. J Drugs Dermatol 13: 1053-1056. Link: http://bit.ly/2I010p7

Copyright: @ 2020 Webster J, et al. This is an open-access article distributed under the terms of the Creative Commons Attribution License, which permits unrestricted use distribution, and reproduction in any medium, provided the original author and source are credited. 